\title{
Review
}

\section{Maggot Therapy: The Science and Implication for CAM Part II-Maggots Combat Infection}

\author{
Yamni Nigam ${ }^{1}$, Alyson Bexfield ${ }^{1,2}$, Stephen Thomas ${ }^{3}$ and Norman Arthur Ratcliffe ${ }^{2}$ \\ ${ }^{1}$ School of Health Science, University of Wales Swansea, Singleton Park, Swansea SA2 8PP, UK, \\ ${ }^{2}$ Department of Biological Sciences, University of Wales Swansea, Singleton Park, Swansea SA2 8PP, UK and \\ ${ }^{3}$ Biosurgical Research Unit (SMTL), Princess of Wales Hospital, Coity Road, Bridgend CF31 1RQ, UK
}

\begin{abstract}
Maggot therapy employs the use of freshly emerged, sterile larvae of the common green-bottle fly, Phaenicia (Lucilia) sericata, and is a form of artificially induced myiasis in a controlled clinical situation. Maggot therapy has the following three core beneficial effects on a wound: debridement, disinfection and enhanced healing. In part II of this review article, we discuss clinical infections and the evidence supporting the potent antibacterial action of maggot secretions. Enhancement of wound healing by maggots is discussed along with the future of this highly successful, often controversial, alternative treatment.
\end{abstract}

Keywords: maggot debridement therapy - MRSA - antimicrobial - Lucilia sericata - wounds

\section{Introduction II-The Rebirth of Maggot Therapy}

The recent resurgence and reintroduction of maggot therapy stems from the steep rise in the emergence of antibioticresistant strains of bacteria, and the need for an effective nonsurgical method of wound debridement. This was begun in the late 1980s and early 1990s, mainly for treating untreatable wounds in California (1-3), and was closely followed by increased use in the UK, Israel and Europe. Currently, several specialist laboratories produce maggots for clinical and research purposes. Maggots are supplied to clinical centers worldwide for the treatment of chronic wounds, such as leg ulcers, pressure sores, diabetic and necrotic ulcers, as well as infected surgical wounds, burns and trauma injuries. In the last decade, thousands of patients all over the world have had their wounds treated with maggots, so maggot therapy is well and truly recognized by many clinicians as an important adjunct to conventional medicine. In Part II of this review, we consider how maggots may kill microbial agents infecting wounds and attempts to isolate antibacterial factors,

For reprints and all correspondence: Yamni Nigam, University of Wales Swansea, Singleton Park, Swansea SA2 8PP, UK. E-mail:

Y.Nigam@swansea.ac.uk including anti-methicillin resistant Staphylococcus aureus (anti-MRSA) agents, from maggot secretions. Finally, the role of maggots in stimulating the wound-healing process is described as are the limitations in the use of maggots in the clinical situation.

\section{How do Maggots Combat Clinical Infections?}

How maggots combat clinical infection in wounds has been studied intensely over the years. Several mechanisms have been suggested, including simple mechanical irrigation of the wound by increased exudate, the production of which is stimulated by larvae ingesting liquefied necrotic tissue, or by dilution of wound discharge following wound lavage by the maggots' own secretions/excretions $(4,5)$. The excretion of a waste product, ammonia, by Phaenicia sericata was also believed to be responsible for combating bacterial infections, since ammonia increases wound $\mathrm{pH}$, resulting in alkaline conditions unfavorable to many bacterial species $(6,7)$. In addition, larvae of $P$. sericata carry in their midgut a commensal, Proteus mirabilis. These commensals produce agents such as phenylacetic acid (PAA) and phenylacetaldehyde (PAL), with known antibacterial properties (8). While $P$. mirabilis 
is an endosymbiont of screw worms and several blow flies, and may contribute to controlling other intestinal and wound flora (9), the participation of these chemicals in combating wound infections is unlikely since aseptically raised, sterile larvae are applied to wounds. In addition, the $\mathrm{pH}$ of maggot secretions is known to be between 8-8.5 $(9,10)$, and Erdmann (9) revealed that at alkaline $\mathrm{pH}$ the antibacterial potential of PAA is low, while PAL is unstable and therefore limited as a bactericide. A more likely explanation of how maggots combat wound infection is that larvae ingest wound bacteria, which are killed as they pass through the maggot's digestive tract. Such destruction of ingested microbes was reported by Robinson and Norwood (11), who noted that while the stomach and crop were heavily contaminated with viable bacteria the hindgut was sterile. This was later confirmed by Mumcuoglu et al. (12), who followed the fate of ingested fluorescent Escherichia coli in the alimentary tract of $P$. sericata using confocal microscopy.

\section{Maggots Secret Potent Bactericide}

In 1935, Simmons led a study of the antibacterial activity of elimination products from living maggots, revealing the presence of a potent bactericide present in maggot secretions $(13,14)$. The sterility of the hindgut led Simmons to believe that this antibacterial activity would be present in substances excreted with fecal matter. For his study, Simmons collected externalized secretions from 3-day-old, nonsterile, P. sericata, reared on decaying beef. After collection, the material was autoclaved; the thermal stability of the antibacterial substance permitted the use of non-sterile larvae. Incidentally, Simmons had tried to work with sterile larvae, but found excretions from aseptically raised larvae were much less potent than those collected from non-sterile maggots. When his autoclaved excretions were tested on $S$. aureus, he reported that bacteria exposed to excretions in vitro for 5-10 min failed to produce colonies on agar plates, even after a 7 day incubation period, indicating that the excretions exhibited a strong and rapid disinfection action $(13,14)$.

In addition to $S$. aureus, Simmons $(13,14)$ showed in vitro antibacterial activity against Streptococcus pyogenes, Streptococcus faecalis, Streptococcus mitor, Clostridium perfringens, Proteus vulgaris and Eberthella (Salmonella) typhi. In 1957, Pavillard and Wright (15) confirmed the presence of antibacterial agents in heat-sterilized maggot excretions from the blowfly Phormia terraenavae, which were active against $S$. aureus, $C$. perfringens and species of Streptococcus. In this study, the active fraction was isolated using paper chromatography, and relatively pure samples of the antibacterial fraction obtained by using a cellulose column. The exact nature of this active factor was never identified, although injections of the fraction into mice protected them against subsequent intraperitoneal inoculation with type 1 Pneumococci (15).

\section{More Advanced Technology Analyzes Methicillin Resistant S. aureus}

More recently, using high-performance liquid chromatography, an antibacterial agent from maggots was partially purified using Micrococcus luteus as the indicator bacteria (16). This factor, reported to possess a molecular weight of $6000 \mathrm{Da}$, was digested by proteases, caused efflux of potassium ions from bacterial cells, and exhibited a wide spectrum of antibacterial activity against many resident pathogenic strains including MRSA. In addition, Thomas et al. (10) conducted the first study using secretions from aseptically raised larvae whose immunological profile was unaffected by microbial contact. In this study, activity was demonstrated against S. aureus, Pseudomonas aeruginosa, Streptococcus group A and group B, and a clinical isolate of MRSA. Following the work of Thomas et al. (10) our own team has further investigated this activity. The choice of antibacterial assay proved vital in the detection of microbial killing. Bexfield et al. (17) showed that the use of standard antibacterial assays, such as the zone of inhibition assay, were ineffective when using maggot excretions. Separation of maggot excretions into three molecular mass fractions $(>10 \mathrm{kDa}, 0.5-10 \mathrm{kDa}$ and $<500$ Da) using ultrafiltration revealed the presence of two discrete antibacterial moieties (17). Significant antibacterial activity of the $0.5-10 \mathrm{kDa}$ and the $<500 \mathrm{Da}$ ultrafiltration fractions was demonstrated against $S$. aureus using a turbidometric assay, whilst the $>10 \mathrm{kDa}$ fraction was free of antibacterial activity (Fig. 1A).

\section{Specificity of the Antibacterial $<500 \mathrm{Da}$ Fraction and Clinical Implication}

When assayed against MRSA, however, antibacterial activity was detected only within the $<500 \mathrm{Da}$ fraction (Fig. 1B), suggesting that this fraction contains the most potent antibacterial component within maggot secretions/excretions. The identity of the $<500 \mathrm{Da}$ is currently under investigation. Further analysis of the $0.5-10 \mathrm{kDa}$ fraction indicated that it contains a heat-stable, protease-sensitive antibacterial molecule of $0.5-3 \mathrm{kDa}$ in size, possibly an antibacterial peptide. Maggots therefore have a repertoire of externalized defenses against microbes that we are only just identifying, and whose presence supports clinical findings and the continued use of maggots. Isolation, identification and synthesis of maggot-derived antibacterial compounds may also allow the benefits of maggot therapy to be applied to wider clinical use, such as in the treatment of systemic infections. In addition, many Dipteran species, such as Phormia terranovae (18) are known to express antimicrobial peptides (AMPs). AMPs, for example, defensin (18), are small, heat-stable, usually cationic, peptides induced in response to invading pathogens and tissue damage $(19,20)$. Defensins are not only involved directly in antimicrobial immunity but may also have a role in wound healing through, for example, cytokine regulation and enhanced phagocytosis (21). 

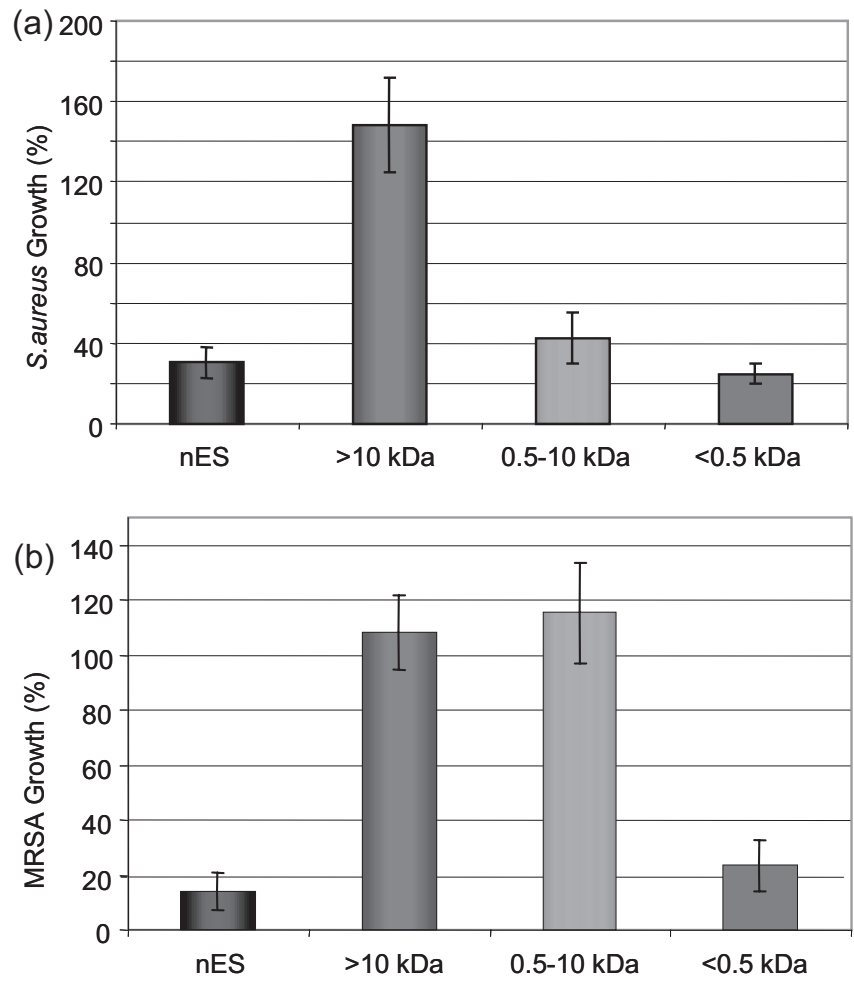

Figure 1. Antibacterial activity of L. sericata excretions/secretions (ES) ultrafiltration fractions. Native ES (nES) from third instar larvae was sequentially fractionated through ultrafiltration membranes with 10 and $0.5 \mathrm{kDa}$ molecular weight cut-offs. Fractions generated were assayed for antibacterial activity using a turbidometric assay. Antibacterial activity was associated with the $0.5-10 \mathrm{kDa}$ and $<0.5 \mathrm{kDa}$ fractions when tested against $S$. aureus (A). When bioassayed against MRSA (B), only the $0.5 \mathrm{kDa}$ fraction demonstrated antibacterial activity. Error bars $=$ SEM. $n=3$ [Fig. $3 \mathrm{~b}$ modified from Bexfield et al. (52)].

\section{Enhanced Healing (Maggots as Healers)}

Among the characteristics of maggot therapy are rapidity of healing and the appearance of healthy new extracellular matrix (ECM) (granulation tissue). The healing of wounds is a complex, interactive process. Three groups of bioactive molecules, growth factors, cytokines and chemokines are important regulators of wound healing. They are all proteins or polypeptides, synthesized and released locally (22). Following injury, the wound healing process is initiated by the release of a number of soluble mediators from platelets during hemostasis. These include growth factors. Growth factors are important mitogens which stimulate the proliferation and chemotaxis of wound cells (epithelial cells, fibroblasts and vascular endothelial cells) as well as regulating their function (22).

\section{Growth Factors, Cytokines and Chemokines Influence Healing}

Growth factors, such as platelet-derived growth factor (PDGF), epidermal growth factor (EGF), fibroblast growth factor (FGF) and transforming growth factor (TGF), are produced upon blood clotting and diffuse from the wound site to rapidly recruit inflammatory cells to the injured area. Cytokines are involved in the chemotaxis, proliferation and differentiation of leucocytes and chemokines direct the recruitment and activation of leukocytes during inflammation. There is considerable overlap between the actions and target cells of these molecules. The presence of growth factors, cytokines and chemokines provide significant vasodilation and increased capillary permeability to the wound site, allowing the infusion of recruited polymorphonuclear leucocytes (PMNs) and macrophages. These cells play an important role in debridement of the wound site, but also continue to secrete additional growth factors including TGF- $\beta$, TGF- $\alpha$ and basic FGF (bFGF) (22).

In a chronic wound, however, one in which procession through the normal stages of healing is not occurring, overexpression of certain ECM components including fibrin, may scavenge growth factors and signal molecules involved in promoting wound repair (23). In addition, reduced levels of growth factors such as TGF- $\alpha$ and TGF- $\beta$ may also contribute to a stagnancy in healing (22). What then, in this particular environment, do maggots offer to aid healing? First, maggots help the healing process (as already discussed) by proteolytic digestion of necrotic tissue and disinfection. Second, researchers have suggested that maggots exhibit other, more direct, mechanisms which contribute to the enhanced healing of wounds (24-26).

\section{Maggots Assist Wound Healing}

Earlier theories of how maggots encouraged wound healing centered on their ability to physically stimulate viable tissue in the wound by crawling motions (27), a notion also supported by the observation that maggots enhanced tissue oxygenation in chronic wounds (26). Other scientists suggested that the actions of allantoin (2,5-Dioxo-4-imadazolidinyl urea) (28) or ammonia biocarbonate (7) could be responsible for the abundant growth of granulation tissue. Lucilia excrete their nitrogenous waste as $10 \%$ allantoin and 90\% ammonia (29) and clinical trials performed by Robinson (28) using allantoin did indeed demonstrate stimulated growth of local granulation tissue. The quantity of ammonia produced by aseptically raised maggots was shown to be sufficient to account for an increase in wound $\mathrm{pH}$ from acid to neutral or slightly alkaline at pH 7 or $8(6,30)$. Robinson (7) also carried out successful clinical tests using 1-2\% solutions of ammonia carbonate and ammonia bicarbonate showing the promotion of healing in purulent and indolent wounds.

\section{Role of EGF and Remodeling of ECM}

Recently, Prete (31) investigated the growth-stimulating effects of alimentary secretions and hemolymph from the blowfly $P$. sericata on human fibroblast tissue. Prete found that both extracts stimulated the proliferation of fibroblasts, and, furthermore, in the presence of stimulatory concentrations of EGF, maggot extracts significantly caused additional 
fibroblast growth. This led to the suggestion that maggot extracts may either operate to stimulate fibroplasia through a different mechanism to that of EGF, or may have a synergistic effect (31).

Other researchers suggest that since fibroblast proliferation is only one aspect of granulation tissue formation, it seems likely that additional mechanisms may be involved. Chambers et al. (32) claim that when maggots are introduced into necrotic wounds, they potentially influence wound healing events with a combination of excretory/secretory (ES) proteases which are involved in the remodeling of ECM components. These workers suggest that proteinases secreted by maggots cause the lysis of fibrin/ECM, releasing proliferative effectors, e.g. fibronectin fragments, which cause the enhanced healing effects seen with maggots. The researchers believe that one particular type of enzyme with trypsin-like activity may play a role in protease activated receptor (PAR)-mediated activation of proliferation or cytokine secretion within a wound (32).

\section{Is There a Role for $\boldsymbol{P}$. sericata ES Products and Interaction with ECM?}

Recently, a quite exciting and extensive piece of research has investigated the behavior of human dermal fibroblasts (seeded on ECM components, e.g. fibronectin or collagen) in the presence of $P$. sericata ES products (33). According to these results maggot ES caused changes in fibroblast adhesion and spreading upon ECM protein surfaces. The authors concluded that Phaenicia ES affected the integrity of the protein surface, especially that of fibronectin, whilst maintaining cell viability. Maggot ES incubated with fibronectin progressively uncovered or released small, independently bioactive peptides of fibronectin which modulate fibroblast behavior, proliferation and migration, thus enhancing new tissue formation and thereby the acceleration of wound healing (33). More recently, this team have also shown that $P$. sericata ES promote fibroblast migration on a fibronectin-coated surface, postulating that a probable mechanism by which maggots enhance tissue formation may be by the promotion of fibroblast motility (34).

\section{Secretion of Cytokines by Maggots and Role of Growth Factors}

Other workers have investigated the potential of maggots to secrete cytokines in vitro. Mumcuoglu et al. (12) reported finding high levels of gamma-interferon and interleukin (IL-10) in maggot secretions, concluding that this could contribute to the increase in granulation observed in debrided tissue in which maggots were present. Most recently, Nibbering (35) showed that endothelial cells, incubated with maggot secretions, exhibited an increase in cytokine production, including IL-8, IL-10 and the growth factor beta-FGF.

A final theory on exactly how maggots stimulate granulation in a wound implicates growth factors and their undeniable role in wound healing. Investigations into the presence of growth factors in invertebrates have revealed considerable conservation of these molecules throughout evolution, and the occurrence of several growth factors, e.g. EGF, TGF, with homology to human growth factors have been demonstrated $(36,37)$. Since growth factors are involved in invertebrate development, and exhibit homology to human factors, then are insect growth factors such as those of Phaenicia involved in the healing of maggot-infested wounds?

Indeed, Livingston (38) stated that 'maggots (fly embryos) were of necessity rich in complex organic substances, which, because of their embryonic nature, are growth-stimulating'. In a preliminary attempt to examine cross-reactivity of human growth factors with maggot excretions, we have undertaken a series of preliminary experiments. Maggot excretions were screened for the presence of the growth factors such as EGF, PDGF, TGF- $\beta$, FGF and IGF (insulin-like growth factor) using western blotting. We found specific cross-reactivity between maggot excretions and the anti-FGF antibody (Tew et al., unpublished data). Even though this is a preliminary result, it is consistent with the maggot extract-mediated stimulation of fibroplasia reported by (31). Finally, we are clear that maggots do produce accelerated healing in wounds that have remained stationary and non-healing for a long time. More work needs to be undertaken if some of the mystery surrounding this clinical observation is to be uncovered.

\section{Conclusions: Future of Maggot Therapy in Relation to CAM}

It is questionable as to whether maggot therapy, a unique, inexpensive, natural way of attempting to combat wound infections, will ever obtain the recognition it deserves. The main problem remains, not patient compliance, but willingness by physicians and surgeons to implement it. Many doctors see maggot therapy as an 'antiquated treatment' (although this treatment is now available on NHS prescriptions in the UK, and US medical insurance companies do reimburse patients for maggot therapy (39). Others describe maggot therapy as a step backwards, which owing to social disappointment, will never regain the popularity of the 1930s (40). It is, however, interesting that there is no such disapproval shown by nursing staff, both district and hospital based, who find the techniques and application of maggots on to a wound, easy to learn. There is also no such disapproval from patients, and often (e.g. in US) there are a lot more patients requesting maggot therapy than there are practitioners willing to apply it (39).

\section{Extensions and Applications of Invertebrate Immune Systems: An Approach to CAM}

Even though research into the science behind the success of maggot therapy is proliferating, much more laboratory evidence into the exact mechanisms of healing and of the nature of the antibacterial molecules are needed. Only with this evidence will the cynics and doubters be convinced that maggots are nature's remarkable answer to festering, 
infected, non-healing wounds. Until we know more and can harness their secrets, maggots will continue in the face of their critics, to wriggle, wander, debride, cleanse and heal our wounds. In the larger context, their effects are related to the emergence of bioprospecting, in particular the use of natural products from animals (41-43). The present results from experiments with maggot excretory products extend our knowledge regarding the range of invertebrate molecules available for the treatment of human diseases (44-46).

\section{Acknowledgments}

We wish to thank Bro Morgannwg and Action Medical Research (grant number AP1010) for financial support. The work was partly funded by the Bro Morgannwg NHS Trust.

\section{References}

1. Sherman RA, Wyle FA, Vulpe M, Wishnow R, Iturrino J, Watson M, et al. Maggot therapy for treating pressure sores in spinal cord patients. J Am Paraplegia Soc 1991;14:200 (Abstr.).

2. Sherman RA, Wyle FA, Vulpe M, Levsen L, Castillo L. The utility of maggot therapy for treating pressure sores. J Am Paraplegia Soc 1993;16:269 (Abstr.).

3. Sherman RA, Wyle F, Vulpe M. Maggot debridement therapy for treating pressure ulcers in spinal cord injury patients. J Spinal Cord Med 1995;18: $71-4$.

4. Mumcuoglu KY, Ingber A, Gilead L, Stessman J, Friedman R, Schulman H, et al. Maggot therapy for the treatment of intractable wounds. Int J Dermatol 1999;38:623-7.

5. Sherman RA, Hall MJR, Thomas S. Medicinal maggots: an ancient remedy for some contemporary afflictions. Anпи Rev Entomol 2000;45: 55-81.

6. Messer FC, McClellan R. Surgical maggots. A study of their functions in wound healing. J Lab Clin Med 1935;20:1219-26.

7. Robinson W. Ammonium bicarbonate secreted by surgical maggots stimulates healing in purulent wounds. Am J Surg 1940;47:111-5.

8. Erdmann GR, Khalil SKW. Isolation and identification of two antibacterial agents produced by a strain of Proteus mirabilis isolated from larvae of the screwworm (Cochliomyia hominivorax) (Diptera: Calliphoridae). J Med Entomol 1986;23:208-11.

9. Erdmann ER. Antibacterial action of myiasis-causing flies. Parasitol Today 1987;3:214-6.

10. Thomas S, Andrews A, Hay P, Bourgoise S. The anti-microbial activity of maggot secretions: results of a preliminary study. J Tissue Viability 1999;9:127-32.

11. Robinson W, Norwood VH. Destruction of pyogenic bacteria in the alimentary tract of surgical maggots implanted in infected wounds. J Lab Clin Med 1934;19:581-6.

12. Mumcuoglu K, Miller J, Mumcuoglu M, Friger F, Tarshis M. Destruction of bacteria in the digestive tract of the maggot of Lucilia sericata (Diptera: Calliphoridae). J Med Entomol 2001;38:161-6.

13. Simmons S. A bactericidal principle in excretions of surgical maggots which destroys important etiological agents of pyogenic infections. J Bacteriol 1935;30:253-67.

14. Simmons S. The bactericidal properties of excretions of the maggot of Lucilia sericata. Bull Entomol Res 1935;26:559-63.

15. Pavillard ER, Wright EA. An antibiotic from maggots. Nature 1957; 180: 916-7.

16. Friedman E, Shaharabany M, Ravin S, Golomb E, Gollop N. Partially Purified Antibacterial Agent from Maggots Displays a Wide Range of Antibacterial Activity Presented at 3rd International Conference on Biotherapy. 1998. Jerusalem, Israel.

17. Bexfield A, Nigam Y, Thomas S, Ratcliffe NA. Detection and partial characterisation of two antibacterial factors from the excretions/secretions of the medicinal maggot Lucilia sericata and their activity against methicillin-resistant Staphylococcus aureus (MRSA). Microbes Infect 2004;6:1297-304.

18. Lambert J, Keppi E, Dimarq JL, Wicker C, Reichhart JM, Dunbar B, et al. Insect immunity: isolation from immune blood of the dipteran Phormia terranovae of two insect antibacterial peptides with sequence homology to rabbit lung macrophage bactericidal peptides. PNAS 1989;86:262-6.

19. Vizioli J, Salzet M. Antimicrobial peptides from animals: focus on invertebrates. Trends Pharmacol Sci 2002;23:494-6.

20. Zasloff M. Antimicrobial peptides of multicellular organisms. Nature 2002;415:389-95.

21. Yang D, Biragyn A, Kwak LW, Oppenheim JJ. Mammalian defensins in immunity: more than just microbicidal. Trends Immunol 2002;23: 291-6.

22. Schultz GS, Sibbald RG, Falanga V, Ayello EA, Dowsett C, Harding K, et al. Wound bed preparation: a systematic approach to wound management. Wound Repair Regen 2003;11:1-28.

23. Falanga V, Grinnell F, Gilchrist B, Maddox YT, Moshell A. Workshop on the pathogenesis of chronic wounds. J Invest Dermatol 1994;102: 125-7.

24. Wollina U, Liebold K, Schmidt W-D, Hartmann M, Fassler D. Biosurgery supports granulation and debridement in chronic wounds-clinical data and remittance spectroscopy measurement. Int J Dermatol 2002;41: 635-9.

25. Sherman RA. Maggot therapy for treating diabetic foot ulcers unresponsive to conventional therapy. Diabetes Care 2003;26:446-51.

26. Wollina U, Karte K, Herold C, Looks A. Biosurgery in wound healingthe renaissance of maggot therapy. J Euro Acad Derm 2000;14:285-9.

27. Buchman J, Blair JE. Maggots and their use in the treatment of chronic osteomyelitis. Surg Gynecol Obstet 1932;55:177-90.

28. Robinson W. Stimulation of healing in non-healing wounds by allantoin in maggot secretions and of wide biological distribution. J Bone Joint Surg 1935; $17: 267-71$

29. Chapman RF. Chemical communication: pheromones and chemicals with interspecific significance. In: Chapman RF (ed). The Insects. Structure and Function. Cambridge University Press, 1998, 704-40.

30. Mumcuoglu KY. Clinical applications for maggots in wound care. Am J Derm 2001;2:219-27.

31. Prete PE. Growth effects of Phaenicia sericata larval extracts on fibroblasts: mechanism for wound healing by maggot therapy. Life Sci 1997;60:505-10.

32. Chambers L, Woodrow S, Brown AP, Harris PD, Philips D, Hall M, et al. Degradation of extracellular matrix componets by defined proteinases from the greenbottle larva Lucilia sericata used for the clinical debridement of non-healing wounds. Br J Dermatol 2003;148:14-23.

33. Horobin AJ, Shakesheff KM, Woodrow S, Robinson C, Pritchard DI Maggots and wound healing: an investigation of the effects of secretions from Lucilia sericata larvae upon interactions between human dermal fibroblasts and extracellular matrix components. $\mathrm{Br} J$ Dermatol $2003 ; 148: 923-33$.

34. Horobin AJ, Shakesheff KM, Pritchard DI. Maggots and wound healing: an investigation of the effects of secretions from Lucilia sericata larvae upon the migration of human dermal fibroblasts over a fibronectin-coated surface. Wound Repair Regen 2005;13:422-33.

35. Nibbering P. Effects of Maggot Excrete on Human Endothelial Cells Livesymposium Biotherape Conference. : 2004Neu-Ulm, Germany.

36. Franchini A, Kletsas D, Ottaviani E. Presence of PDGF and TGF- $\beta$ immunoreactive molecules in invertebrate and vertebrate immunocytes: an evolutionary approach. Histochem J 1996;28:599-605.

37. Ottaviani E, Franchini A, Kletsas D. Platelet-derived growth factor and transforming growth factor- $\beta$ in invertebrate immune and neuroendocrine interactions: another sign of conversation in evolution. Comp Biochem Physiol Part C 2001;129:295-306.

38. Livingston SK. The therapeutic active principle of maggots with a description of its clinical application in 567 cases. J Bone Joint Surg 1936;18:751-6.

39. Bonn D. Maggot therapy: an alternative for wound infection. Lancet 2000;356:1174.

40. Bunkis J, Gherini S, Walton RL. Maggot therapy revisited. West J Med $1985 ; 142: 554-6$.

41. Cooper EL. Commentary on traditional and modern biomedical propecting: Part II-the benefits by Werner E.G. Muller, Heinz C, Schroder, Matthias Weins, Sanja Perovic-Ottstadt, Renato Batel and Isabel M. Muller. Evid Based Complement Alternat Med 2004;1:207-9. 
42. Muller WEG, Batel R, Schroder HC, Muller IM. Traditional and modern biomedical prospecting: Part I-the history. Evid Based Complement Alternat Med 2004;1:71-82.

43. Roch P, Beschin A, Bernard E. Antiprotozoan and antiviral activites of non-cytotoxic truncated and variant analogues of mussel defensin. Evid Based Complement Alternat Med 2004;1:167-74.

44. Ratcliffe NA, Rowley AF, Fitzgerald SW, Rhodes CP. Invertebrate immunity-basic concepts and recent advances. Int Rev Cytol 1985;97: $183-350$.
45. Dimarcq J-L. Pharma-entomology: when bugs become drugs. Drug Discov Today 2003;8:107-10.

46. Whitten MMA, Tew IF, Lee BL, Ratcliffe NA. A novel role for an insect apolipoprotein (Apolipophorin III) in beta-1,3-glucan pattern recognition and cellular encapsulation reactions. J Immunol 2004;172: $2177-85$.

Received September 13, 2005; accepted March 23, 2006 


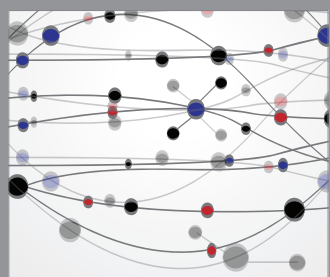

The Scientific World Journal
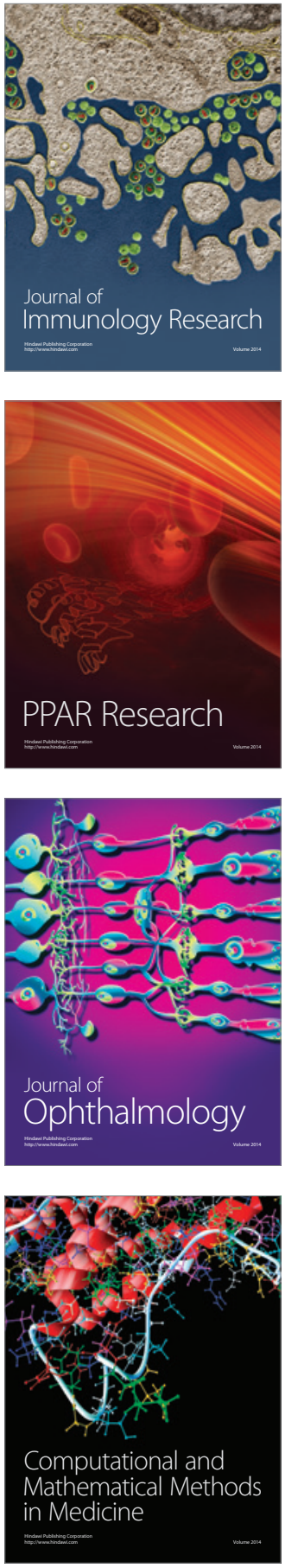

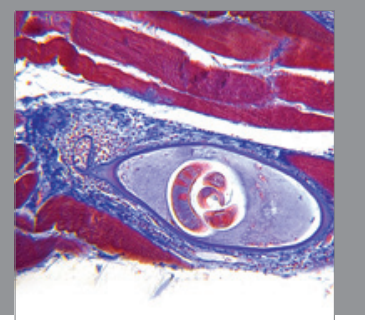

Gastroenterology

Research and Practice
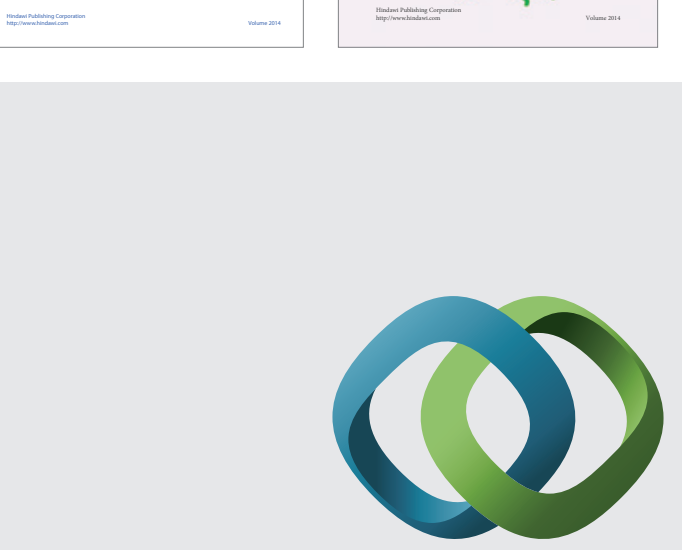

\section{Hindawi}

Submit your manuscripts at

http://www.hindawi.com
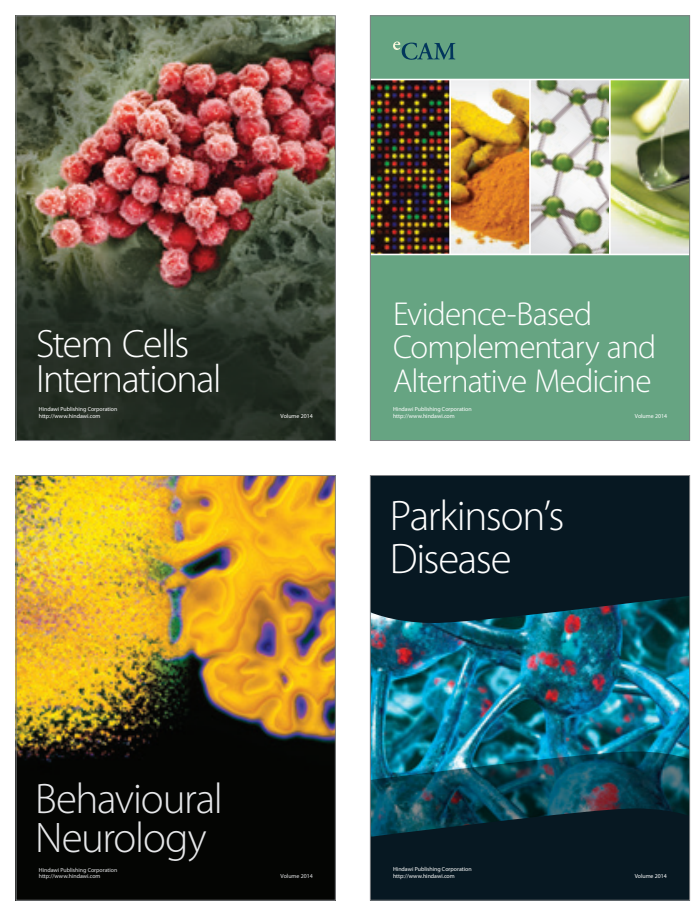

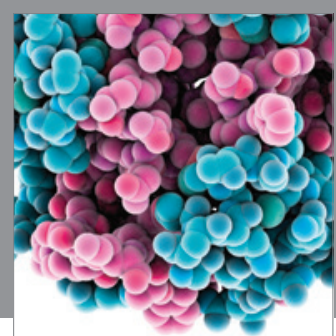

Journal of
Diabetes Research

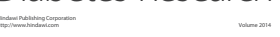

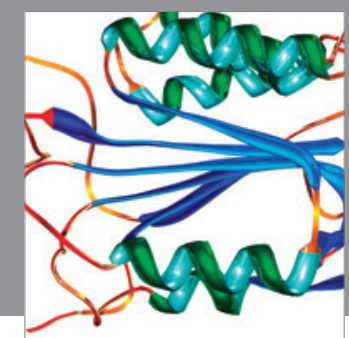

Disease Markers
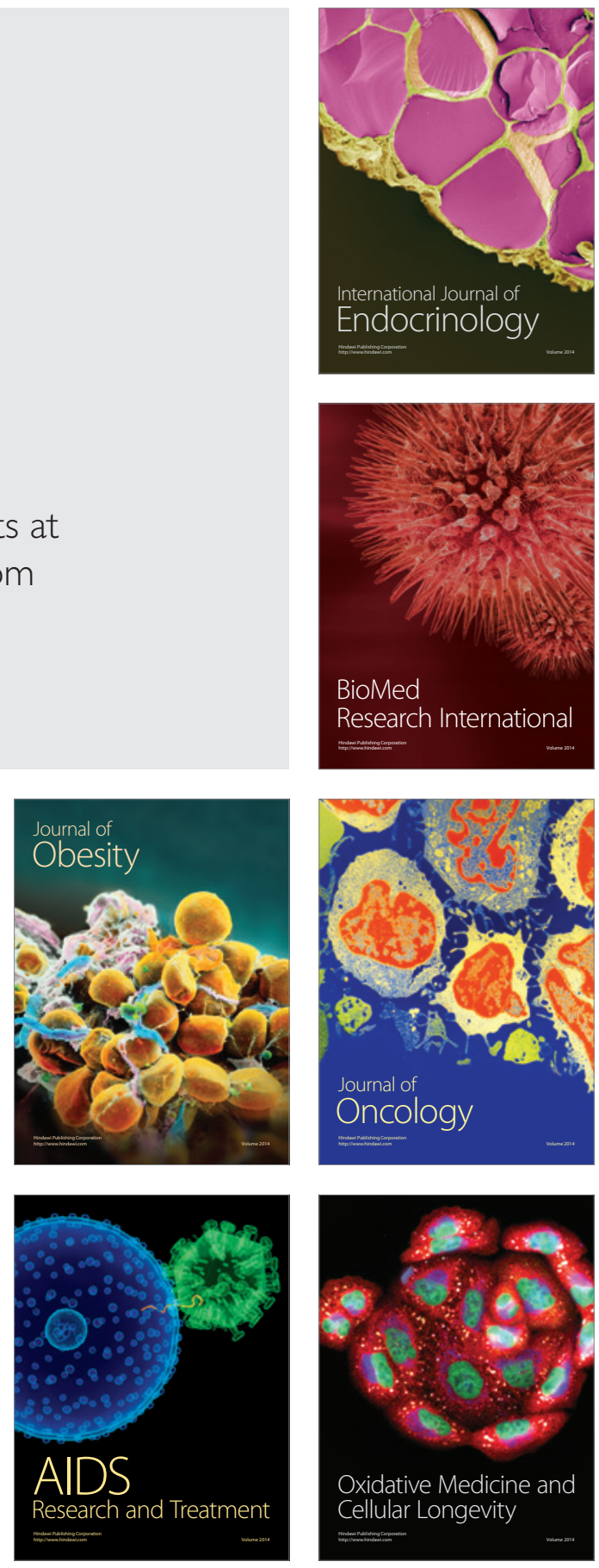